\title{
LA BELLEZA Y LA FILOSOFÍA
}

Alberto Monar

Estudiante de Filosofía y Pedagogía, UPS-Quito

\section{Introducción}

Antes de iniciar esta aproximación al arte desde la filosofía quisiera citar una de las frases más preciosas de Hegel sobre el arte: "es el medio gracias al cual el hombre exterioriza lo que es"; es decir, la idea se plasma en la realidad, por ello el arte es la mejor forma de expresar lo que nuestras ideas tratan de atribuir a la realidad.

Al hablar de arte, llego a puntualizar que la belleza es su expresión majestuosa. Es la condición en que el ser humano trata de plasmar exquisitamente toda esa carga de emoción y fascinación que le produce el mundo exterior. Mundo que en un principio se le mostró como desconocido, pero que le motivó el deseo y afán de simbolizarlo.

Debo empezar estableciendo la relación entre el arte y la filosofía; para ello cito una descripción del arte de Aristóteles: "la finalidad del arte es dar cuerpo a la esencia secreta de las cosas"; es decir, es buscar la cosa en sí misma, exteriorizarla y hacerle apetecible a nuestros sentidos; sentir como somático la esencia desde nuestra corporalidad, sensibilidad e inteligencia. 


\section{Revisión histórica desde la cultura helénica}

El término belleza — del griego kalia (bello)—, se entiende como el orden que posee dentro de sí un objeto, pero también algo que genera orden al exterior de sí mismo.

En la antigüedad, las dos grandes interpretaciones de belleza vienen de Platón y Aristóteles, quienes influirán en la forma de comprenderla e interpretarla, pues sus enfoques tienen mucha vigencia hasta nuestros días.

Para Platón la belleza está por encima del mundo sensible, se relaciona únicamente con la realidad eidética y suprasensible (bien y belleza); es decir, reside en la idea y sólo desde esta se puede entender. La visión dualista que posee Platón desacreditará a lo sensible frente a lo ideal, la belleza será reminiscencia y participará del alma racional, en desmedro de lo sensible y emocional.

Las cosas de este mundo participan en mayor o menor grado de la idea de belleza. En el mundo de las ideas está la belleza absoluta, la belleza en sí; en este mundo sensible no hay cosas bellas, a menos que participen de la idea del mundo suprasensible.

Como reacción a este postulado y concepción de la belleza, surgirá Aristóteles, quien calificará la belleza como algo que está dentro de la esencia de las cosas pero cuya manifestación es lo sensible: "Es bello lo que es valioso por sí mismo y lo que a la vez nos agrada”. El filosofo convirtió la imagen en concepto, sustituyendo una interpretación intuitiva por una definición.

El realismo aristotélico permitirá tomar en cuenta el mundo sensible y considerarlo como expresión de la esencia; a partir de él, la belleza será una forma de manifestación corpórea. Por lo tanto, esta manifestación 
se realiza en todo ente, considerándose a la belleza como un elemento trascendental de este, que es captada por nuestra sensibilidad y llevada a nuestro intelecto.

¿Cómo surgen las posturas objetivas y subjetivas de la belleza?

Siguiendo el desarrollo histórico del pensamiento filosófico, la concepción de belleza de la Edad Media seguirá fluctuando entre el platonismo y el aristotelismo; pero al llegar Descartes, éste mirará la belleza como producto del orden y exactitud de la razón, completamente alejado de lo sensible (los sentidos son engañosos), y creado por la res cogitans.

La belleza vuelve a caer en un nuevo dualismo, pero esta vez su forma de comprenderse y su fundamento es la razón, alejada de las realidades sensibles y en desmedro de éstas.

Simultáneamente, para el empirismo inglés la belleza sólo es posible como imagen débil de la experiencia con los objetos, reducida al mundo psíquico y emocional. La belleza relegada al mundo empírico será una simple imagen de la cosa, pero habrá que volver a la experiencia para no perder la belleza del objeto.

Ante esto la belleza sólo será un momento de la experiencia del sujeto con el mundo sensible, y ella dependerá de cada experiencia individual, descartando un criterio objetivo y único de la misma.

Como continuidad e intento de síntesis de estas dos posturas filosóficas tenemos la posición kantiana sobre la belleza, pues para Kant la belleza es una realidad racional con cierta apertura a lo fenoménico. La belleza tiene que ser agradable a la razón y apetecible a los sentidos. Lo agradable es aquello que place a los sentidos en la 
sensación: "Todo lo que place justamente en lo que place es agradable".

Si bien lo bello y lo bueno son sentimientos diferentes, ambos coinciden en que pretenden ser universales y necesarios. La visión de la belleza es en Kant un concepto que supera la relación con lo fenoménico.

Lo bello es aquello que place sin interés alguno. El desinterés es la condición de posibilidad de la experiencia estética. La belleza sería una de las categorías de la estética vista como trascendental (creación del sujeto desde la razón).

Dentro de la estética trascendental las categorías de tiempo y espacio están dentro del mundo fenoménico, pero son creaciones del sujeto, que ordena la realidad desde la razón.

El intento kantiano de establecer la belleza como categoría es partir de la realidad sensible, creada por la razón, y tratar de ser la máxima afirmación de la razón sobre la realidad (universal y necesaria).

El meollo del asunto consistirá en que la razón tendrá el poder de crear lo que considere como bello, y la razón como construcción de cada sujeto hará imposible establecer normas universales para la belleza, pues dependerá de cada hombre y su razón.

De aquí en más, la estética será parte de la reflexión filosófica, pero relegada al plano del pensamiento. Posteriormente Hegel definirá a la belleza como la manifestación del espíritu. El espiritu es toda la creación del pensamiento lógico que se impone a la realidad. La belleza artística es superior cuantitativamente a la belleza natural, por ser obra del espíritu (pensamiento lógico).

La belleza natural es inferior a la belleza artística, ya que esta es naturaleza inconsciente. Hay que tener en cuenta que en la teoría del arte de Hegel, la verdad se 
relaciona con el espiritu, por eso dice que la belleza artística es verdadera porque es espíritu.

Esto ocasionará un intercambio entre lo que se piensa como belleza y lo que no lo es, pues esta sólo será imposición de la idea sobre la naturaleza, todo dependerá de las ideas de cada sujeto sobre lo que es bello y no lo es; es decir, del pensamiento subjetivo.

\section{La absolutización de la estética en el pensamien- to: Nietzsche}

En la continuidad del pensamiento dentro de la historia de la filosofía, lo subjetivo seguirá dependiendo de las ideas, la realidad natural es el lugar de la imposición e intercambio de la belleza y la no belleza que se dan como realidades del pensamiento lógico, hasta el punto que se produce un intercambio dentro del mismo pensamiento; la belleza sobrepasa la verdad: el punto de interés filosófico no es lo verdadero sino lo que se puede pensar e imponer como belleza a la realidad.

El intercambio de la idea de belleza y no belleza se apoderará por completo de la reflexión filosófica, Nietzsche afirmará que: "la belleza es la actividad fundamental de la vida", poniendo la estética en el centro de su filosofía. Este lugar privilegiado de la estética se mantiene a lo largo de toda su reflexión filosófica e influirá en la posmodernidad.

El pensamiento que plantea es estético, pues persigue lo bello, pero este es una creación de la razón que se impone a lo que se piensa como existencia. Para crear es necesaria la voluntad de poder; es decir, la justificación estética de la existencia, el arte como estimulante de la vida, serán los determinantes que se apoderarán de la reflexión filosófica, y darán el giro de lo racional a lo irra- 
cional. Los aspectos estéticos tomarán a la verdad como algo relativo y sin importancia.

Lo único importante es cómo se manifiesta el pensamiento, no los niveles de objetividad, que ya no interesan. La belleza es algo que no tiene normas, se impone al pensamiento y a la realidad.

\section{La propuesta de la Teoría Crítica: revisión histó-} rica y la intencionalidad socio-cultural de la belleza

La propuesta de la Escuela de Frankfurt nos ayudará a tomar en cuenta la revisión histórica desde los aspectos culturales y de desarrollo del pensamiento, pero agregándole la cuestión socio-política que será influyente dentro de la manifestación y delimitación del arte.

En la crítica al planteamiento subjetivista e irracionalista de Nietzsche se tratará de establecer criterios de mayor rigurosidad sobre la belleza y el arte; la reflexión desde la realidad objetiva y dinámica permitirá volver a superar el irracionalismo y subjetivismo.

Para Adorno: "el arte sin reflexión es una fantasía anacrónica”, por lo tanto, al reflexionar se trata de volver a establecer el criterio socio-cultural que promovió el arte. Los aspectos culturales y sociales que no fueron tomados en cuenta por los filósofos anteriores dentro de sus corrientes y que son determinantes para la teoría crítica explican que "el arte y la belleza podrían tener su contenido en su propia transitoriedad"; es decir, que la necesidad de tomar en cuenta lo histórico y cultural nos ayudará a comprender el desarrollo del arte y la belleza en el transcurso del pensamiento y la necesidad de reflexionar sobre estos como aspiraciones de la razón y así lograr un mejor conocimiento de la sociedad. 
El arte necesita de la filosofía para que le ayude a interpretar y decir lo que él no puede, y esta posibilidad de hablar sobre el arte se debe precisamente a que él no habla. Por eso el arte como expresión del hombre y la sociedad debe ser analizado desde las causas que lo motivan y las razones que lo justifican.

Desde este postulado, la teoría crítica ataca al sistema intransferible y le abre al arte la capacidad de ser un elemento de la crítica del pensamiento social, cultural, científico, antropológico, etcétera.

Cuando la crítica de la configuración de una obra llega a percibir en ella el espíritu y a confrontar los diferentes momentos entre sí y también con el espíritu que en ellos se muestra, está acercándose a su verdad más allá de la configuración estética. Por eso es necesaria la crítica. Ella es la que reconoce en el espíritu de las obras su contenido de verdad.

La filosofía debe reflexionar sobre el arte, no abandonarlo al simple acto del pensamiento, sino buscar las verdades o realidades que están de fondo, en qué contextos se gesta y qué aspiraciones y propósitos tiene.

\section{Conclusión}

Hemos visto que la estética aborda el difícil problema de la belleza y de su relación con los objetos artísticos y de estos con la naturaleza y el hombre. Aquí surge la pregunta: ¿Puede ser considerado el pensamiento filosófico como expresión artística?, o ¿cómo construir filosofía desde el arte?

El telhos de las obras de arte es un lenguaje cuyas palabras no están incluidas en esa visión lingüística normal, ni han sido dictadas por una universalidad preestablecida. Creo que el esfuerzo de este breve ensayo es ayu- 
dar a despertar la conciencia del filósofo para una justa valoración de la estética en nuestra praxis. Construir filosofía desde el arte es un nuevo desafío, no sólo para los grandes intelectuales, sino para todas y todos los que gustamos de la reflexión filosófica.

El arte fue la forma de hacer filosofía durante largo tiempo, y nuestra exigencia hoy es volver a recuperar este espacio, volver a dar a la razón a la capacidad de ser creativa en sus exposiciones, pero superando los criterios subjetivistas que aparecen en la modernidad.

La belleza de la razón, en su capacidad de comprensión e interpretación, debe ser re-potenciada, no absolutizada; por ello, es necesario el dialogo con la historia, la antropología, la política; es decir, con nuestra realidad.

Establecer los fines e interés del arte nos permitirá sobrepasar el espejismo de lo subjetivo y tener contacto amplio con la realidad para conocerla y expresarla de manera agradable a los sentidos y apetecible a la razón.

\section{Bibliografía}

ADORNO, Theodoro

2004 Teoría Estética. Obra completa. Madrid: Akal. BENJAMÍN, Walter

2003 La obra de arte en la época de su reproductividad técnica. México: Editorial Itaca.

FERRATER, Mora

1994 Diccionario de Filosofía. Tomo I. Barcelona: Editorial Ariel. 